\title{
Challenges of Strategy Implementation on Performance of Constituency Development Fund Projects in Kenya: A Case of Marakwet West Constituency
}

\author{
Jacob M. Katamei ${ }^{1}$, Gedion A. Omwono ${ }^{1} \&$ Sister Lucy Wanza ${ }^{1}$ \\ ${ }^{1}$ The Catholic University of Eastern Africa, Nairobi, Kenya \\ Correspondence: Jacob M. Katamei, P. O. Box 7702-30100, Eldoret, Kenya. Tel: 254-722-669-036. E-mail: \\ jacobmerew@yahoo.com
}

Received: March 14, 2015

Accepted: April 8, 2015

Online Published: April 21, 2015

doi:10.5430/ijba.v6n3p48

URL: http://dx.doi.org/10.5430/ijba.v6n3p48

\begin{abstract}
Constituency development fund was adopted by the government of Kenya in 2003 as a people centered approach to development. The study examined the challenges in strategy implementation on performance of Constituency Development fund Projects and established measures. The research questions were: to what extent did leadership, cultural receptivity, structural facilitation and communication posed a challenge to the performance of Constituency Development Fund projects? And what measures should be taken? It adopted descriptive research design. Targeted 263 Management Committees. Stratified random sampling was used to select 79 respondents. Questionnaire and Interview Guide were used to collect data. Descriptive statistics was used for data analysis. The findings were leadership, cultural receptivity; structural factors and communication were identified to be challenges to performance of projects. Measures established included training of various committees through workshops, incorporating well educated people in various committees, involving all stakeholders in the implementation processes and adopting effective and efficient methods of transferring information. The study recommended the need for management to develop an organizational culture that allows successful implementation of Constituency Development Fund projects.
\end{abstract}

Keywords: challenges, performance, measures, projects, leadership, culture, structure, communication

\section{Introduction}

\subsection{Background to the Problem}

The success of a project is critical to achieving development agenda in the local communities across the world. It is also understood that implementation of projects is fundamental if the project objectives and success are to be achieved. Various projects could be initiated to transform social, political and economic well-being of citizens in a particular country. To address various economic injustices and low development levels in Kenya since independence, the Government of Kenya has initiated various reforms aimed at transforming the country to a middle-income country by 2030 .

\subsection{Concept of Strategy Implementation}

Strategy implementation involves organization of the firm's resources and motivation of the staff to achieve objectives. The environmental conditions facing many firms have changed rapidly. Today's global competitive environment is complex, dynamic, and largely unpredictable. To deal with this unprecedented level of change, a lot of thought has been focused on strategy implementation. Strategic management is about managing the future and effective strategy implementation is crucial as it directs the attention and actions of an organization. The assessment of strategy implementation processes becomes crucial for practitioners and researchers alike in order to conduct and evaluate different implementation processes (Thompson et al. 2007).

In recent years, organizations have sought to create greater organizational flexibility in responding to environmental turbulence by moving away from hierarchical structures to more modular forms (Balogun, 2003). Responsibility, resources and power in firms have been the subject of decentralization. Given an intensifying competitive environment, it is regularly asserted that the critical determinant in the success and, definitely, the survival of the 
firm is the successful implementation of marketing strategies (Chebet, 2005). The role and tasks of those employees charged with strategy implementation, the mid-level managers in these new restructured organizations, is under scrutiny.

Considering the global scenario, there has been a shift in thinking and in the United States of America the idea of new federalism has gained great currency with each other than ever before causing them to focus more on economic development and less on social welfare. CDF resembles the USA congressional allocation generally called 'pork barrel', 'ear marks' or 'members terms' in national and state level policy making.

The practice to decentralize development similar to Constituency Development Fund (CDF) was first adopted in India, but gained prominence when Kenya established CDF in 2003. Based on the perceived success of the Kenyan model and various political and historical drivers, the trend has spread to other African countries and across the world in recent years. The following countries have adopted some forms of Constituency Development Fund: Southern Sudan, The Philippines, Honduras, Nepal, Pakistan, Jamaica, Solomon Islands, Tanzania, Malawi, Namibia, Zambia, Uganda, Ghana and Malaysia, with the brain child being India.

\subsection{Performance of Constituency Development Fund Projects}

The Constituency Development Fund (CDF) in Kenya was established through CDF Act 2003 and Amended in 2007. $\mathrm{CDF}$ is one of the devolved funds meant to achieve rapid socio-economic development at the constituency level through financing locally prioritized projects and enhanced community participation. Studies conducted across the country on the 210 constituencies by the CDF Board and National Anti-Corruption Steering Committee, GOK (2008) indicated that since its inception in 2003, CDF has facilitated the implementation of a number of local level development projects aimed at poverty reduction and socio - economic development of people. The program is designed to fight poverty through the implementation of development projects at the local level and particularly those that provide basic needs such as Education, Healthcare, Water, Roads, Security and Bridges. The CDF's operational structure and the mosaic expenditure decisions at the parliamentary jurisdictions have been characterized as innovative and ingenious (Kimenyi, 2005). In the last 10 years of its operation, CDF funds have largely been used to fund projects in four key sectors: Education, Water, Health, and Roads (GOK: CDF Allocation Summary, 2007).

While yearly CDF allocations may not seem handsome, the impact both physically and socially at the community level has been phenomenal. For instance, many schools have been built and equipped by CDF. It has also aided the government's policy of providing free primary school Education. In the health sector, many hospitals, dispensaries, maternity wings within existing health facilities, and clinics have been built in record time. This has helped decongest larger district level hospitals. In terms of infrastructure, many roads that were previously neglected and impassable have been upgraded and made assessable. This has reduced transportation costs to the market for locally produced goods. Socially, the traditional role of women of fetching water from rivers and streams has been transformed with the many water boreholes that have been drilled and are now reliable water points, and have notably reduced the distance women cover to fetch water in rural areas. Additionally, CDF has helped crime prone areas to construct police posts which the Central Government has been quick to bring into operation to reaffirm its commitment to public safety. The operational structure of the CDF allows local people to make their own expenditure decisions that reflect their tastes and preferences to maximize their welfare.. The CDF projects must be community driven to ensure that the prospective benefits are available across a wide section of the residents of a particular area.

The CDF Act 2007 recognizes the Project Management Committee as the committee responsible for implementation of a project at the constituency level. The legal provision of the establishment and operation of the Act suggests that the fund is essentially a model for decentralization of development planning and implementation. The Constituency Development Fund (CDF) was created to fight poverty at the grassroots level through the implementation of community based projects which have the long term effect of improving the peoples' economic well being and relieving members of parliament from the heavy demands of fund-raising for projects which ought to be financed through the Consolidated Fund.

\subsection{An Overview of Marakwet West Constituency}

Marakwet West Constituency is an electoral constituency in Kenya. It is one of the four constituencies in Elgeyo Marakwet County. The constituency has six wards, all of which elect members of county assembly for the Elgeyo Marakwet assembly. The constituency was established prior to the 1997 elections. As at the 2009 census, the population of the constituency was estimated at 108,374 people. The constituency occupies about 80,460 square kilometers. 
The constituency prides itself in the water resource which broadly serves Eldoret residents of Uasin-Gishu County. In addition, it has a potential in agricultural production like fruit farming, sheep and horticulture alongside other micro and macro ventures. It also hosts several middle level colleges, over 20 secondary schools, over 60 primary schools and over 30 health facilities spread across it. However, the infrastructural network across the constituency is generally depressing (Marakwet West Constituency Strategic Plan, 2008 - 2012).

\subsection{State of CDF Projects in Marakwet West Constituency}

CDF projects in Marakwet West Constituency lack their own structures for disclosure and accountability since these are handled by central government officials. The Kenya Public Service and especially procurement and supplies departments have often been accused of inefficiency and ineffectiveness. This is worsened by the near complete absence of civil participation in the implementation of projects.

Implementation of any strategy calls for brilliant communication and understanding it. The CDF Act is silent on professional skills and competencies for project management committees, which implies a significant lack of communication for sound management of planning, implementation, monitoring and evaluation of development projects. It can be expected that PMC members who lack relevant skills, competencies and communication skills are more likely to be manipulated to participate or to turn a blind eye to malpractices. Mapesa and Kibua (2006) call it 'being used as rubber stamps' for predetermined decisions whether or not they understand. As such, politicians and central government officials at the district headquarters have been left as principal decision-makers to the disadvantage of the beneficiaries in Marakwet West Constituency.

Generally, a well formulated strategy merely provides superior performance for the firm when they are efficiently implemented. In order to answer research questions of this study the researcher will present a conceptual framework showing CDF projects performance and challenges in strategy implementation. For better strategy implementation the management skills are undoubtedly important. As a matter of fact, successful strategy implementation is associated with efficient implementation. Failed strategy implementation can be associated with challenges in strategy implementation and can be expensive to an organization in terms of time lost, money spent, low employee morale, diminished trust, and lack of faith in the senior management.

Challenges in strategy implementation are therefore the key issue of interest. Among the challenges that threaten effective implementation are leadership, culture receptivity, structural facilitation, and communication. This study therefore attempted to examine these challenges in strategy implementation on performance of CDF projects in Kenya with special reference to Marakwet West Constituency.

\subsection{Statement of the Problem}

During the implementation of projects, disconnect may arise between commitments made at different levels and actual implementation on the ground. These commitments are designed to achieve the projects' desired results and determine the success or failure of the projects. The performance of a project can be defined in terms of timeliness, budget restriction, stakeholders' satisfaction and accountability. On the other hand, the failure of a project entails poor leadership, poor structure facilitation, wanting culture receptivity and lack of communication among other challenges.

The Constituency Development Fund (CDF) in Kenya is a strategy initiative which is gaining a widespread acceptance across the populace. Its resultant observance has made CDF projects vulnerable to severe scrutiny especially in its implementation stage for example existence of several stalled projects, delayed completions of projects, cost ineffectiveness, structural dissatisfaction of stakeholders and lack of communication leading to challenges such as leadership, structural facilitation, culture receptivity, and communication which were examined in this study. These must be re-aligned and enhanced in order to curb their effect on performance of CDF projects.

A study was carried out by Kimeli (2008) on the challenges of strategy implementation at the Kenya Revenue Authority (KRA). The study found out that an incompatible organization structure, poor communication, inconsistent policies, lack of employee involvement and lack of sufficient funding hindered the success of strategy implementation at the KRA. Studies that have been conducted have not focused on the challenges in strategy implementation to performance of CDF projects in Marakwet West Constituency and thus the current study examined these challenges in strategy implementation to performance of CDF projects and established measures to be adopted to cope up with these challenges in the constituency under study.

\subsection{Research Questions}

The study was guided by the following research questions; 
1. To what extent does leadership pose a challenge to performance of Constituency Development Fund projects at Marakwet West Constituency?

2. How does culture receptivity pose a challenge to performance of Constituency Development Fund projects at Marakwet West Constituency?

3. To what extent does structural facilitation pose a challenge to performance of Constituency Development Fund projects at Marakwet West Constituency?

4. Does communication pose a challenge to performance of Constituency Development Fund projects at Marakwet West Constituency?

5. What measures should be taken by Marakwet West Constituency to cope with challenges of strategy implementation to performance of Constituency Development Fund projects?

\section{Review of Literature}

\subsection{The Concept of Strategy}

The concept of strategy is well linked to strategic management, which is a set of decisions and actions that result in the formulation and implementation of plans designed to achieve organization's objectives.

Neluheni et al, (2014) while studying the role of quality strategic planning on organizational success in South Africa, conducted a research which realized that when cause-and-effect is applied to categorization of strategies, it follows that process drives quality, which in turn drives rate of success or failure in the implementation of the strategic plan. The research methodology adopted was the descriptive research. A self-administered survey questionnaire was used to collect data in which the respondents were asked to fill by themselves. The findings of the research confirmed that a well-conceived and a good quality strategy lead to flawless implementation, organizational competitiveness and effectiveness. In conclusion therefore, although it is recognized that there are numerous contextual factors that impact on the successful implementation of a strategic plan, it is postulated that the quality of the strategic plan is core to its success.

Thompson, et al (2007) pointed out that strategy is a management's action plan for running the business and conducting operations in order to achieve the targeted levels of organizational performance. Thus it is about how to move the organization in the intended direction by employing combination of competitive approaches on how to strengthen the market position and boost performance in order to achieve the targeted goals and objectives. In public organizations, the goal setting processes are conflicting since there is no common bottom line such as profit, which makes measuring performance complex and difficult.

In a nut shell therefore, strategy implementation rests in the hands of the employees or any other individual in charge. If these individuals are not motivated either through incentives or reducing legal constraints, expectation are challenges to strategy implementation impacting on performance of CDF projects.

\subsection{Strategic Management}

Dess, Lumpkin and Taylor (2005) this study identified the relationship between institutionalization level, strategic management level and human resource management level in family businesses. It also investigated whether the demographic characteristics of family businesses affect their levels of institutionalization, strategic management and human resource management. It gathered data from owners or authorized staff of family businesses located in the North-East Anatolia sub economic region of Turkey. The study found that Strategic Management requires incorporating both short-term and long-term perspectives. This implies that managers must maintain both a vision for the future as well as a focus on the present operating needs for the organization. Strategic Management also involves recognition of trade-offs between effectiveness and efficiency and while managers must allocate and use resources wisely, they must still direct their efforts toward the attainment of overall organizational objectives. Making strategic decisions is another important attribute of Strategic Management. Such decisions are made by top-management since only the top management understands the broad implications of the decisions.

\subsection{Strategy Implementation}

Nyaguthii, et al (2013), while studying the Influence of Community Participation on Successful Implementation of Constituency Development Fund Projects in Mwea Constituency, Kenya, conducted a research aimed at determining the extent to which involvement of the community on identification, implementation, monitoring and evaluation of community-based projects affected the successful implementation of Constituency Development Fund projects. The study employed Descriptive research study where descriptive statistics guided data analysis. The findings revealed 
that most of Mwea residents do not participate in the management of Community Development Fund projects, leading to failure in implementation. The study recommended that community members, whether influential or not, should be involved in identification, implementation, monitoring and evaluation of the CDF projects to boost success.

However, it is important to note that the community is the beneficiary of the implementation process; when challenges of strategy implementation are identified it will be easier to provide measures which will ease strategy implementation. The current study which was carried out at Marakwet West Constituency identified the challenges and provided measures which would help enhance performance of CDF projects.

Eppler et al (2008), while studying on Making Strategy Work: A Literature Review on the Factors influencing Strategy Implementation, wrote the Working Paper 2/2008 which argued that most of the definitions of strategy implementation in the literature stress the role of top management while others stress the external environment, without mentioning the (non-managerial) employees and their crucial role in turning strategic plans into results. The study therefore, defined strategy implementation as a dynamic, iterative and complex process, which comprised of a series of decisions and activities undertaken by managers and employees. Effective Strategy implementation can be achieved if it is made all inclusive for example allowing participation of non executive officers such as employees or Project Management Committees in the case of CDF.

Lehner (2004), while studying Strategy Implementation Tactics as Response to Organizational, Strategy and Environmental Imperatives, used a questionnaire-based measure of implementation tactics testing a sample of 136 Upper-Austrian firms by focusing on implementation projects or strategy related issues. For a sub-sample $(\mathrm{n}=60)$ a moderated regression analysis on implementation tactics with measures of organizational structure, the environment, the strategy, and the interaction between environment and strategy as independent variables was performed. The study observed that, based on previous literature in the fields of strategy implementation and leadership, research tactics for strategy implementation are identified. Three categories proved empirically valid in this study: autocratic tactics, participative tactics and tactics which rely on the given culture of the organization. The study was based on the assumption that implementation in general is dependent on environmental, strategic and organizational variables. In this sense implementation tactics can be interpreted as genuine organizational behaviour based on the assumption that implementation in general is dependent on the environment, and various strategic and organizational variables which are important in strategy implementation if adopted would enhance effective strategy implementation in the community level which was a constituency in the current study, if not it may pose a challenge to performance of CDF projects.

\subsection{Factors That Influence Strategy Implementation}

Implementation of strategy is a way in which a company creates organizational arrangement that allows it to pursue its strategy most effectively. It is not enough to just formulate an appropriate strategy or to come up with an appropriate strategic plan, rather, effective strategy implementation, the strategy must be supported by decisions regarding appropriate organization structure, leadership, culture and the systems for rewarding performance as well as monitoring and controlling organizational action (Pearce \& Robinson, 2007).

Noble (1999), The Eclectic Roots of Strategy Implementation Research. Noble in the conclusion of the literature review says this field is too little explored and that's why it required a deeper reflection on the meaning of critical factors and certain aspects to define a useful implementation framework for practitioners. To start, he suggests there are two general dimensions in strategy implementation: the structural view (firm structure and control mechanisms) and the interpersonal process view (strategic consensus, behaviours, organizational climate, communication and interaction processes). In another article: Building the strategy implementation network, the same author suggests several managerial levers (goals, organizational structure, leadership, communications and incentives) essential in carrying out the implementation across the next implementation stages: pre-implementation, organizing the implementation efforts, managing the implementation process and maximizing cross-functional performance. However the current research came up with ways in which challenges can be managed to enhance performance of CDF projects.

Okumu (2003) in his study introduced an interesting framework which is partly based on the works of other researchers and his own research. From his analysis, factors that can be identified as influencing strategy implementation are: strategy development, environmental uncertainty, organizational structure, culture, leadership, operational planning, resource allocation, people, communication, and control. Based on these factors, he created a framework for strategy implementation consisting of four elements namely: content (strategic decision, multiple project implementation), context (internal context: organizational structure, organizational culture, and leadership; 
external context including environmental uncertainty in the general and task environment), process (operational planning, resources allocation, people, communication and control) and outcome (tangible and intangible outcomes of the project). The current research agrees with Okumu's work on strategy implementation challenges; however the current research provided mitigation to these challenges.

Thompson et al (2007), mention that structure is the means by which the organization seeks to achieve its strategic objectives and implement strategies. Thus it refers to the basic way in which the organization's different activities are organized. Successful strategy implementation depends largely on the primary organizational structure that identifies key activities within the firm and the manner in which they will be coordinated to achieve the firm's strategic purpose.

It is imperatively true that well organized structures during strategy implementation gives a positive impact to performance of CDF projects but poorly organized structures as identified in the current study posed a challenge to performance of CDF projects.

Schaap (2006) carried out an empirical study on whether effective senior-level leadership behaviors are directly related to successful strategy implementation and argued that senior-level leaders who have been trained in or studied strategic planning and implementation are more likely to meet the performance standards of the company. However as identified in the current study majority of the leaders were not well trained on issues to do with strategic planning and implementation thus posed a challenge to performance of CDF projects.

According to Pearce \& Robinson (1997), the role of the Chief Executive Officer (CEO) and the assignment of key managers are fundamentally important to successful implementation of strategy. The CEO's actions and perceived commitment to the strategy significantly influence the commitment of the subordinate managers to implementation strategy. The CEO therefore represents an important source of clarification, guidance and adjustment during implementation process. Most of the project management identified leaders' commitment as lacking in the current research.

Pearce and Robinson (2007), define organizational culture as a set of important assumptions or shared beliefs and values that organizational members hold in common. These beliefs influence opinions and actions within the organization among its members. Culture involves the learning and transmission of knowledge, beliefs and patterns of behavior over time. It helps in nurturing and dissemination of core values and establishes rules on how people should behave within the organization. Every organization has its own unique culture or work climate which is the product of the core values and business principles that are espoused by the executives.

Strong culturally approved behaviors and practices are nurtured and are developed by strong leaders who establish values, principles, and practices that are consistent with the strategic requirements. Such cultures contribute greatly to strategy implementation and where such strong cultures are lacking then it posed a challenge to performance of CDF projects.

According to Viseras et al (2005), strategy implementation success depends largely on people management. Thus the selection and development of key managers in an organization should be carefully carried out. People who have been with the organization for an extended period of time continue to reinforce and perpetuate the current culture, they are empowered by it and go to considerable lengths to reinforce it as a key element in sustaining continued success.

Their association with the organization is usually strongly entrenched, emphasize key themes or dominant values, encourage dissemination of stories and legends about core values in the organization and help institutionalize practices that reinforce desired beliefs and values.

Rapert et al (2002) all agree that communication is one of the most important parts of strategy implementation. Communication is important both in the formulation process as a means of creating consensus and understanding and in the continuous implementation process and it is imperative successful implementation. Particularly, when vertical communication is frequent, strategic consensus (shared understanding about strategic priorities) is enhanced and an organization's performance improves. Training, knowledge dissemination and learning during the process of strategy implementation are also enhanced through communication.

In the current study communication posed a challenge to performance of CDF projects since information was poorly delivered and conceived differently by individuals especially on individual roles.

Kitutu (2009) carried out a study that focused on the challenges of strategy at the Ministry of Public Works in Kenya. The findings of the study revealed that culture, poor compensation, lack of fit between strategy and structure, in sufficient communication, lack of coordination and support, outdated information technology, wrong strategic 
choices, government interference and regulations, poor management of resources, global trends in the industry and inadequate personnel skills posed challenges on strategy implementation in the organization. However the study could not provide ways of overcoming these challenges. The current study provided the ways to mitigate these challenges.

Kibathi (2009) undertook a study on challenges of strategy implementation at Oxfam Great Britain-Kenya. Kibathi categorized subsystems in the organization and referred to them as functional areas which included human resource, finance, administration, logistics and communication. Under human resource she pointed out that budget constraints, employee turnover, inadequate technical skills, and unwillingness of employees to work under harsh conditions were challenges faced in this functional area. Under finance she noted that inadequate resource and limited access to these resources posed a challenge. Administration faced the challenge of the tall structure. While inadequate human capital, unrealistic objectives and lack of sufficient preparation were challenges faced by the logistics area, and lastly, under communications, conflicting proprieties and inadequate coordination were the major challenges. This research did not provide ways to overcome these identified challenges, but were provided for by the current study.

Mullei (2009) focused on challenges of liberalization by DT Dobie Limited and found out that Employee incompetence, high customs duty, stringent import regulation and procedures and fluctuation in foreign currency were the major challenges of strategy implementation. All these studies are proof that strategy implementation are unique to the context and emphasize the need to look at the challenges of effective strategic implementation in Marakwet West Constituency Development Fund.

\subsection{Challenges in Implementing Strategies}

Nutt (1986) studied strategic decisions in organizations located in USA and Canada and concluded that half of the strategic decisions fail to attain their initial objectives mainly because of the problems during strategy implementation process. Even though the stream of research which deals with strategic decision making is well developed, there are few empirical studies on strategy implementation. Several scholars have attempted to investigate challenges to effective implementation of strategies in firms but could not provide ways of mitigating these challenges.

Beer and Eisenstat (2000) identified some of the main problems for effectively implementing strategies as: ineffective senior management team, unclear strategies and conflicting priorities, poor coordination across functions, poor vertical communication and inadequate down- the- line leadership skills and development. This study also fails to provide mitigation to the challenges which will enhance performance of such projects like CDF.

\subsection{Successful Strategy Implementation on Performance}

In the attempt to identify the attributes of successful strategy implementation on performance, the study of Miller (1997) after studying eleven strategic decisions implemented by six organizations belonging to the manufacturing and service sectors identified ten factors which according to him were prerequisite to successfully implementing strategic decisions which influenced performance. They are: backing, assembling, specificity, cultural receptivity, propitiousness, familiarity, priority, resource availability, structural facilitation and flexibility. The study also found out that the factors which have the most significant influence on the success of strategy implementation which influence performance were backing, assembling, specificity, cultural receptivity and propitiousness. When these factors are not appropriately aligned it leads to strategic implementation challenges thus poor performance of projects.

Ireland and Hickson (2003) identified eight variables which have a significant impact on the success of strategy implementation which influence performance and they grouped them into two categories which represent two distinct approaches to successful strategy implementation namely the experience-based approach and the readiness-based approach. The variables representing experienced-approach were to assess ability, resourcing, familiarity, acceptability, and specificity, while the variables representing readiness-based approach were structural facilitation, priority and receptivity. This study suggested that organizations have two options to follow for implementing the strategies namely the planned option which was experienced-based and the prioritized option which was readiness option.

The literature review suggests that just a few papers involving strategy implementation have been published in the leading journals. For example, Ireland and Hickson (2003) examined the relationship between strategy implementation and organizational performance. It was also found out that strategy implementation was not studied along with challenging variables in any of the studies hence the nature of the relationship between these variables and strategy implementation on performance of CDF projects is unclear and the reason for undertaking current study. 
As indicated earlier, the study conducted by Ireland and Hickson (2003) has made a significant contribution to the literature by providing a set of parsimonious variables which could be used to measure the success of strategy implementation. The contracts proposed by the authors were used in the current study. These included structural facilitation, cultural receptivity, communication (familiarity) and ability (leadership) which were examined in the current study as challenges in strategy implementation on performance of CDF projects.

\subsection{Strategy Implementation on Performance}

Neely (1999) indicates seven reasons that are seen necessary for performance measurement in the organisation - the changing nature of work; increasing competition, specific environment initiatives, quality awards, changing organizational roles, changing external demands, and the power of information technology. Performance measurement is kept also to measure if the right work is done, not only that the work is done right. This study established measures that need to be adopted to cope with strategy implementation challenges in marakwet west constituency which could enhance performance of CDF projects.

\subsection{Critic of the Empirical Review}

Several studies have been done on the challenges of strategic implementation, Neluhemi et al, (2014) while conducting study in South Africa; with self administered questionnaire found that a good quality strategy leads to flawless implementation organizational comprehensiveness and effectiveness. The researcher concluded that, the impact on successful implementation of strategic plan is the core of its success. However, under this study, questionnaire and interview guide were used as data collection instrument. It was found that lack of leadership commitment and cultural receptivity posed greater challenges to commitment and performance due to low implemented beliefs by leaders. This study concluded that culture, leadership and structural communication were challengers to performance of constituency development fund projects.

Kitutu (2009) focused on the challenges of strategy at the Ministry of Public Works in Kenya. The findings of the study revealed that culture, poor compensation, lack of fit between strategy and structure, in sufficient communication, lack of coordination and support, outdated information technology, wrong strategic choices, government interference and regulations, poor management of resources, global trends in the industry and inadequate personnel skills posed challenges on strategy implementation in the organization. However the study could not provide ways of overcoming these challenges. The current study provided the ways to mitigate these challenges.

Mullei (2009) focused on challenges of liberalization by DT Dobie Limited in Kenya and found out that Employee incompetence, high customs duty, stringent import regulation and procedures and fluctuation in foreign currency were the major challenges of strategy implementation. All these studies are proof that strategy implementation are unique to its context and emphasize the need to look at the challenges of effective strategic implementation in Marakwet West Constituency Development Fund.

Ireland and Hickson (2003) examined the relationship between strategy implementation and organizational performance. They did not study strategy implementation along with challenging variables hence the nature of the relationship between these challenging variables and strategy implementation on performance is unclear and the reason for undertaking current study in Marakwet west.

Miller (1997) after surveying eleven strategic decisions implemented by six organizations belonging to the manufacturing and service sectors identified ten factors which according to the study were prerequisite to successfully implementing strategic decisions which influenced performance. The study also found out that the factors which have the most significant influence on the success of strategy implementation which influence performance were backing, assembling, specificity, cultural receptivity and propitiousness. When these factors are not appropriately aligned it leads to strategic implementation challenges thus poor performance of projects. However the current study nevertheless focuses on structural leadership, cultural and communication as some of the challenges to performance of constituency development fund in Marakwet West Constituency.

\section{Research Design and Methodology}

\subsection{Research Design}

The study adopted descriptive research design. According to Mugenda and Mugenda (2003), a descriptive research design determines and reports the way things are. Also Creswell (2003) observed that a descriptive research design is used when data is collected to describe persons, organizations, settings or phenomena. Descriptive design was ideal in this study as the study was carried out within a limited geographical scope and hence it was logistically easier and 
simpler to conduct. The design was appropriate as the study sought information on the existing situation of the CDF and challenges in strategy implementation on performance of CDF projects.

\subsection{Target Population}

The target population for this study was the members of Marakwet West Constituency Development Fund Management committees and the project committees involved in the implementation of CDF projects. This entails all the 15 members of Constituency Development Fund Committee (CDFC), 5 Executive Subcommittee, as well as CDF committees at the location level. There are 15 locations in Marakwet West constituency and every location has a CDF committee of 5 members. Thus the target population of the location committee was 75 people. The study also targeted 168 active Project Management Committees where each project is headed by a chairperson who was targeted forming 168 PMC chairpersons per the existing Audited CDF projects in 2013.The study therefore targeted 263 committee members in total.

\subsection{Sampling Procedure}

According to Mugenda and Mugenda (2003) a sample size of 30\% is considered adequate for descriptive research design to generalize the characteristics being observed. The study therefore sampled 79 respondents $30 \%$ from the target population. For the purposes of the research stratified sampling was used to select the sample for each category, from each category random sampling was used to select the respondent in each category. The sampled respondents included 29 respondents from CDFC, LDC and ESC were interviewed while 50 respondents from PMC participated in answering the questionnaire.

\subsection{Description of Research Instruments}

A structured questionnaire was used which were closed ended, easily guided the respondents as they had to tick from the multiple choice questions. The kind of questions also allowed easier coding of data. Interview guide was also used to collect data from respondents who did not have enough time to fill in a questionnaire. However, the interview was guided by a structured questionnaire. The secondary data was collected from CDF offices, Library and internet.

\section{Findings}

\subsection{Demographic of Respondents}

Out of 50 questionnaires distributed for the study, 48 came back in good condition for analysis. This gave a response rate of $96 \%$. Information about the age, gender, years of experience and level of education was sought in order to check whether these variables had a challenges on implementation of CDF Projects. Again, out of 79 respondents, 46 were male and 33 were females. Most of these respondents (27) were aged above 50. On the experience, 6-10 years had 41 respondents, while 2-5 years were 25. Majority of the respondents had served in CDF long enough and were experienced.

\subsection{Leadership Challenge in Strategy Implementation}

Table 1. Challenges of different aspects of leadership on performance of CDF projects

\begin{tabular}{|c|c|c|c|c|c|c|c|}
\hline ITEM & $\mathbf{S A}$ & $\mathbf{A}$ & MO & $\overline{\mathbf{D}}$ & SD & $\bar{M}$ & STD \\
\hline Leadership lack self driven commitment & 18 & 25 & 5 & 0 & 0 & 4.27 & 0.64 \\
\hline $\begin{array}{l}\text { The leadership inadequate commitment to the } \\
\text { strategic implementation }\end{array}$ & 25 & 20 & 3 & 0 & 0 & 4.42 & 0.65 \\
\hline $\begin{array}{l}\text { The leadership spare time to persuade the } \\
\text { employees }\end{array}$ & 31 & 17 & 0 & 0 & 0 & 4.65 & 0.48 \\
\hline $\begin{array}{l}\text { The leaders demonstrate their willingness to give } \\
\text { loyalty to the implementation process }\end{array}$ & 8 & 22 & 18 & 0 & 0 & 3.79 & 0.71 \\
\hline Lack of leadership backing of implementation & 20 & 25 & 3 & 0 & 0 & 4.35 & 0.60 \\
\hline $\begin{array}{l}\text { Lack of leadership commitment to performing their } \\
\text { roles }\end{array}$ & 32 & 13 & 3 & 0 & 0 & 4.60 & 0.61 \\
\hline
\end{tabular}

KEY: SA-Strongly agreed, A-agreed, MO- moderate, D-disagreed, SD- Strongly Disagreed, M-mean, STDStandard deviation

The study sought to establish the level at which respondents agreed to the above statements, from the findings majority of the PMC chairpersons agreed that lack of manager's commitment to performing their roles leads to the 
lower ranks of PMCs missing support as shown by a mean of 4.60. The study further revealed that respondents agreed that the leaders' lack of commitment to strategic implementation itself is a challenge to performance of CDF projects shown by a mean of 4.42 , and finally that Lack of leaders' backing is the main challenge for project implementation as shown by mean of 4.35 , Leadership devoid of self driven commitment pose a challenge to performance of Constituency Development Fund projects as shown by a mean of 4.27 and finally their leaders do not demonstrate their willingness to give loyalty to the implementation process for the project to succeed as shown by a mean of 3.79. All cases were supported by higher standard deviation which indicates that respondents were of similar opinion except for whether leaders spare time to persuade employees of their ideas for strategy implementation as shown by standard deviation of 0.48 .

\subsection{Cultural Receptivity Challenges in Strategy Implementation}

Table 2. Extent to which different aspects of culture poses a challenge to performance of CDF projects

\begin{tabular}{|c|c|c|c|c|c|c|c|}
\hline CDF Culture & VGE & GE & ME & $\mathbf{L E}$ & NA & $\mathbf{M}$ & STD \\
\hline Poor implemented values and beliefs systems & 7 & 14 & 25 & 2 & 0 & 3.56 & 0.77 \\
\hline Poor Leadership styles. & 13 & 34 & 1 & 0 & 0 & 4.25 & 0.48 \\
\hline $\begin{array}{l}\text { Lack of understanding of CDF project } \\
\text { implementation. }\end{array}$ & 19 & 23 & 6 & 0 & 0 & 4.27 & 0.68 \\
\hline Ignoring the day-to-day business imperatives. & 31 & 17 & 0 & 0 & 0 & 4.65 & 0.48 \\
\hline There is inability to overcome resistance to change & 20 & 25 & 3 & 0 & 0 & 4.35 & 0.60 \\
\hline $\begin{array}{l}\text { Difficulties and obstacles not acknowledged, } \\
\text { recognized or acted upon. }\end{array}$ & 25 & 20 & 3 & 0 & 0 & 4.46 & 0.62 \\
\hline $\begin{array}{l}\text { Conscious and unconscious symbolic acts taken by } \\
\text { leaders. }\end{array}$ & 20 & 19 & 9 & 0 & 0 & 4.23 & 0.75 \\
\hline $\begin{array}{l}\text { Beneficiaries and staff not fully appreciating the } \\
\text { strategy. }\end{array}$ & 26 & 18 & 4 & 0 & 0 & 4.46 & 0.65 \\
\hline
\end{tabular}

KEY: VGE-Very Great Extent, GE-Great Extent, ME- Moderate Extent, LE- Little Extent, NA- Not at All, M-Mean, STD- Standard Deviation

The study sought to establish the extent to which above facets of organization culture poses a challenge to performance of Constituency Development Fund projects in marakwet west constituency. From the findings it was established that, ignoring the day-to-day business imperatives posed a challenge to performance of Constituency Development Fund projects to a very great extent as shown by a mean 4.65, Difficulties and obstacles not acknowledged, recognized and acted upon, Beneficiaries and staff not fully appreciating the strategy both poses a challenge to performance of Constituency Development Fund projects to a great extent as shown by a mean of 4.46 in each case. Inability to overcome resistance to change posed a challenge to performance of Constituency Development Fund projects to a great extent as shown by a mean of 4.35, poor Leadership styles posed a challenge to performance of Constituency Development Fund projects to a great extent as shown by a mean of 4.25, Lack of understanding of CDF project implementation posed a challenge to performance of Constituency Development Fund projects to a great extent as shown by a mean 4.27, Conscious and unconscious symbolic acts taken by leaders (job titles, dress codes, corporate jets, informal meetings) posed a challenge to performance of Constituency Development Fund projects to a great extent as shown by a mean of 4.23 , and finally poorly implemented values and beliefs systems. The norms in the constituency pose challenges to performance of Constituency Development Fund projects as shown by a mean of 3.56 .

\subsection{Structural Challenges in Strategy Implementation}

Table 3. Extent in which Structures posed a challenge to performance of CDF projects

\begin{tabular}{llllllll}
\hline Practices & VGE & GE & ME & LE & NA & M & STD \\
\hline There is Power struggle among different players & 28 & 14 & 3 & 3 & 0 & 4.40 & 0.87 \\
There is Over bureaucracy in CDF management. & 19 & 26 & 3 & 0 & 0 & 4.33 & 0.60 \\
Undefined reporting structure among committees & & & & & & & \\
& 27 & 20 & 1 & 0 & 0 & 4.54 & 0.54 \\
\hline
\end{tabular}

KEY: VGE-Very Great Extent, GE-Great Extent, ME- Moderate Extent, LE- Little Extent, NA- Not at All, M-Mean, STD- Standard Deviation 
The study sought to establish the extent to which the above practices which related to unclear individual responsibilities posed a challenge to performance of Constituency Development Fund projects. From the findings it was found that, Undefined reporting structure between CDFC, Location committees and PMCs posed a challenge to performance of Constituency Development Fund projects to a very great extent as shown by a mean of 4.54, Power struggle among different players in CDF management was a challenge to performance of Constituency Development Fund projects to a very great extent as shown by a mean of 4.40, and finally, Over bureaucracy in CDF management was a challenge to performance of Constituency Development Fund projects to a very great extent as shown by a mean of 4.33 .

\subsection{Communication Challenges in Strategy Implementation}

Table 4. Challenges of different aspects of communication on performance of CDF projects in Marakwet West Constituency

\begin{tabular}{llllllll}
\hline Communication aspects & SA & A & MO & D & SD & M & STD \\
\hline $\begin{array}{l}\text { There is poor vertical and horizontal } \\
\text { communication between different hierarchical } \\
\text { levels and functions. }\end{array}$ & & & & & & & \\
$\begin{array}{l}\text { Ineffective communication of Strategic control } \\
\text { systems. }\end{array}$ & 1 & 11 & 25 & 10 & 2.13 & 0.84 \\
$\begin{array}{l}\text { There exist conflicting priorities in } \\
\text { dissemination of information among different }\end{array}$ & 20 & 28 & 0 & 0 & 0 & 4.42 & 0.5 \\
players in the management of CDF. \\
$\begin{array}{l}\text { Ineffectiveness of communication is a } \\
\text { problem in implementation of CDF projects. }\end{array}$
\end{tabular}

KEY: Strongly agreed A-agreed MO- Moderate D- disagreed SD-Strongly Disagreed M- mean STD- standard deviation.

The study sought to determine the respondents' level of agreement with the above statements that relate to challenges of communication to performance of CDF projects in Kenya. From the findings, majority of the respondents strongly agreed that Communication was essential to ensure that stakeholders across the implementation committees understand their roles. However there was poor vertical and horizontal communication between different hierarchical levels and functions as shown by a mean of 4.77. Others agreed that, ineffectiveness of communication was a challenge to implementation of CDF projects as shown by a mean of 4.60, there exist conflicting priorities in dissemination of information among different players in the management of CDF as shown by a mean 4.42. The study further revealed that respondents disagreed that strategic control systems that provide a mechanism for keeping today's actions in congruence with tomorrow's goals of CDF projects are followed effectively as shown by a mean of 2.13 meaning there is Ineffective communication of Strategic control systems and that There is poor information and knowledge transfer in CDF project implementation as shown by a mean of 1.98 .

\subsection{Measures to Be Adopted by CDF Committees to Cope up with Challenges of Strategy Implementation}

\section{a). Measures to be adopted to cope up with Leadership Challenges}

The following measures were mostly cited by respondents, they include Training of CDF committees through workshops and seminars, Visiting other constituencies to improve knowledge and skills, Electing and appointing well educated persons to CDF committees and offering short training to improve knowledge and skills.

\section{b). Measures to be adopted to cope with Cultural Receptivity Challenges.}

The following were identified by majority of the respondents, they included, the need for all stakeholders to be involved in decision making, Training CDF committees on implementation process, Selection of culture that can ease implementation process and creation of an office to supervise implementation process.

\section{c). Measures to be adopted to cope with Structural Challenges.}

The following structural aspects were identified as the mitigating measure they included, the need for stakeholders to participate in strategy implementation, Reduced bureaucracy at various CDF offices, Dialogue be enhanced in 
various committees, More forums to educate members of society and Stakeholders to participate in the affairs of CDF.

\section{d). Measures to be adopted to cope with Communication Challenge.}

The following factors were mentioned by various committee members as measures which the CDF in the constituency needed to adopt to cope with challenges posed by communication. They included, Utilization of effective and efficient methods of communication, avoiding conflicting dissemination of information and improving knowledge transfer to reach intended persons.

\section{Concussions}

From the findings of the study, the following emerged as the main challenges of strategy implementation on performance of CDF projects;

Leadership challenges in strategic implementation include lack of leadership commitment to give strategic direction, leaders' unwillingness to give energy and loyalty to the implementation process as well as persuading employees to embrace the idea of strategy implementation, and also leader's lack of backing and commitment to performing their roles.

Cultural receptivity challenges included low level of understanding of implementation process, poor managers' leadership style, poorly implemented values and beliefs systems and conscious and unconscious symbolic acts taken by leaders further posed challenges to performance of CDF projects in marakwet west constituency.

Structural challenges of strategic implementation included power struggle, over bureaucracy, and undefined reporting structure have also been identified to pose serious challenges to performance of CDF projects.

Communication challenges of strategy implementation included lack of strategic control systems, lack of priorities among different players, ineffective coordination, additional key tasks and ineffective information system posed challenges to performance of CDF projects. The study therefore indicated that structure, leadership, culture and communication posed challenges to performance of CDF projects.

From the findings various measures have also been established which could help cope with these challenges they include training of various committees through workshops, incorporating well educated people in various committees, involving all stakeholders and utilizing efficient and effective methods of communication in the implementation processes with sole aim of enhancing performance of CDF projects. If more emphasis is placed on these measures the success of strategy implementation at the constituency will greatly improve.

It is hoped that despite the limitations of the study other constituencies especially those in a similar situation with similar characteristics as Marakwet West constituency can use this as a basis to find out other challenges and suitable measures that can be adopted to cope with such challenges.

\subsection{Recommendations}

It is evident that the government has been increasing allocations of CDF and has put policies that allow successful Implementation of CDF projects in Kenya, but due to the aforesaid factors failure rates of CDF projects is still high.

The study recommends that Leaders in CDF committees should demonstrate their willingness to give energy and loyalty to the implementation process for the project to succeed, as it was found that lack of leaders' commitment to performing their roles leads to the lower ranks of employees missing support and guidance through encouragement and lack of understanding of CDF project implementation all of which posed a challenge to performance of Constituency Development Fund projects to a great extent.

The study further recommends that the management of CDF should have an organizational culture that allows successful implementation of CDF project as it was revealed that cultural receptivity posed a challenge to CDF project performance to a great extent. This will help in reducing resistance to change within the CDF committees.

The study also recommends the need to have defined reporting structure between CDFC, Location committees and PMCs in order to reduce power struggle among different players in CDF.

It also recommends the need for the management of CDF projects to have clear, effective and efficient methods of communication to strategy implementation as it was revealed that communication posed a challenge to performance of Constituency Development Fund projects in marakwet west constituency to a great extent. 


\subsection{Recommendations for Further Research}

There has been criticism labeled against the implementation of the fund at the constituency level. It will be important to extend this research to other constituencies in order to establish that the challenges identified are not unique to marakwet west constituency.

It is also advisable to conduct more research on the efficiency of CDF structures and organs in CDF implementation and delivery. The research may include the best practices adopted in the implementation of the strategic plans and extend of adoption. This will bring out issues on transparency and accountability and whether the current CDF structures ensure efficient implementation of the fund and how they can be strengthened.

Another area of importance would be the implementation of other devolved funds like the FPE and the LATF. A study in this area will help to understand how they are being implemented so that any challenges may be brought out and measures established to address them to enable the objectives of these funds to be achieved.

\section{References}

Ahmad, M. S., \& Talip, N. A. (2011). Decentralizations and Participatory Rural Developments: A Literature Review. Contemporary Economics, 5(4), 100-121.

Alexander, L. D. (2005). Successfully implementing strategic decisions. Long Range Planning, 18(3), 91-7. http://dx.doi.org/10.1016/0024-6301(85)90161-X

Balogun, J. (2003). From Blaming the Middle to Harnessing its Potential: Creating Change Intermediaries. British Journal of Management, 14, 69-83. http://dx.doi.org/10.1111/1467-8551.00266

Beer, M., \& Eisenstat, R. A. (1994). The politics of decentralization. London: MacMillan

Burns, N., \& Grove, S. (2001). The practice of nursing Research: Conduct, critique and Utilization. Philadelphia, Pennsylvania: W.B Saunders.

Chebet, S. M. (2005). Efficiency and Efficacy of Kenya's Constituency Development Fund: Theory and Evidence. University of Connecticut working paper $2005-42$.

Cohen, L., Manion, L., \& Morrison, K. (2007). Research Methods in Education (6th ed.). London, Routeldge. $\mathrm{http}: / / \mathrm{dx}$. doi.org/10.1016/S0007-6813(03)00008-9

Creswell, J. W. (2003). Qualitative inquiry and research design (2nd ed.). London: Sage Publication, Inc.

Crook, R. C. (2003). Decentralization and poverty reduction in Africa: The politics of local-central relation. London Public Administration and Development. London: John Wiley and Sons Ltd.

Dess, G. G., Lumpkin, G. T., \& Taylor, M. L. (2005). Strategic Management (2nd ed.). New York: McGraw-Hill Irwin.

Dobni, B. (2003, March, April). Creating a strategy implementation. Business Horizons, 46(2), 43-6.

Emrich, W. (1984). Handbook of Charcoal Making: The Traditional and Industrial Methods. Solar Energy R and D in the European community. Netherlands S. D. Reidel Publishing Co.

Eppler, M. J., Yang, L., Guohui, S. (2008). Making Strategy Work: A Literature Review on the Factors Influencing Strategy Implementation. ICA Working Paper 2/2008.

Government of Kenya. (2007). CDF Allocations, 2003-2007. The constituency development fund website. Retrieved June 12, 2014, from www.cdf.go.ke

GOK. (2003). The Constituencies Development Fund Act. Government Press.

GOK. (2008). The Constituency Development Fund: An Examination of Legal, Structural, Management and Corruption Issues in Kenya. Report by National Anti-Corruption Campaign Steering Committee. Government printers, Nairobi.

Gupta, A. K., \& Govindarajan, V. (2011). Business unit strategy, managerial characteristics and business unit effectiveness at strategy implementation. Academy of Management Journal, 27(1), 25-41. http://dx.doi.org/10.2307/255955

Ireland, R. D., \& Hickson, R. E. (2003). Strategic Management. Ohio: South -Western.

Jhingan, M. L. (1989). Advanced Economic Theory (9th ed.). New Delhi: Kalyani Publishers. 
Kaleem, A., \& Ahmad, S. (2008). Bankers Perception of Electric Banking in Pakistan. Journal of Internet Banking and Commerce, 13(1), 167-183.

Kelvin, K. M. (2012). Factors Influence of uptake HIV Test among civil servants in Tetu District, Nyeri County. Unpublished Thesis. University of Nairobi.

Kerote, A. O. (2007). The Role of the Local Community in the Management of Constituency Development Fund in Sabatia Constituency in Vihiga. University of Nairobi Kenya.

Kibathi, J. (2009). Challenges of Strategy Implementation in Oxfam, Great Britain, Kenya (Unpublished MBA Project). School of Business, University of Nairobi, Kenya.

Kimeli, D. K. (2008). Challenges of Strategy Implementation at Kenya Revenue Authority. Unpublished MBA Project, University of Nairobi.

Kimenyi, M. S. (2005). Efficiency and Efficacy of Kenya's Constituency Development Fund: Theory and Evidence. Working Paper 2005-42: The University of Connecticut.

Kitutu, M. M. (2009). Challenges of Strategy Implementation in the Ministry of Roads Kenya (Unpublished MBA Project). School of Business, University of Nairobi. Kenya.

Kombo, D. K., \& Tromp, D. L. A. (2006). Proposal and thesis writing: an Introduction. Nairobi, Kenya: Paulines Publications, Africa.

Kothari, C. R. (2008). Research Methodology: Methods and Technigues. New Delhi: New Age International LTD.

Lehner, J. (2004). Strategy Implementation Tactics as Response to Organizational, Strategic, and Environmental Imperatives. Management Review, 15, 460-480.

Luo, Z. (2003). Investigation of Tropical Cirrus, Their Variability, Evolution and Relation to Upper Tropospheric Water Vapor. Ph.D. thesis. Columbia University.

Machooka, S. M. (1987). People Participation in Intergrated Rural Development in Peoples Participation in Development in Black Africa. Cameruon. Institute Pan African Pour le Development.

Maina, B. (2005). Monitoring and Evaluation of Support to Decentralization and Local Governance: Kenya. Case Study (working paper No.61): European Centre for Development Policy Management.

Mapesa, B. M., \& Kibua T. N. (2006). An Assessment of the Management and Utilization of the Constituency Development Fund in Kenya. Nairobi: Institute for Policy Analysis and Research.

Marigat, S. K. (2013). The impact of the constituency Development Fund Programmes on public primary schools: A case of Mogotio Constituency. Unpublished Thesis Kenyatta University.

Marakwet West Constituency Strategic Plan, 2013 - 2017.

Marginson, D. E. W. (2002). Management control systems and their effects on strategy formation at middle management levels: evidence from a UK organization. Strategic Management Journal, 23, 1019-31. http://dx.doi.org/10.1002/smj.271

Marshall, W. M. (2003). Rethinking Performance Measurement, Beyond the Balanced Scorecard. Cambridge University Press. New York. United States of America.

Miller, S. (1997). Implementing Strategic Decisions: Four key Success Factors. Organ. Stud., 577-602. http://dx.doi.org/10.1177/017084069701800402

Mugenda, M. O., \& Mugenda, A. (1999). Research methods: Qualitative and Quantitive approaches. African Centre for Technological Studies, Nairobi, Kenya.

Mugenda, O., \& Mugenda, A. (2003). Research Methods; qualitative and quantitative Approaches. African Centre for Technology Studies.

Mullei, K. (2009). Attracting and retaining health workers in rural areas: Investigating Nurse's Views on Rural Posts and Policy Interventions BMC Health Service Research Report.

Mwagwabi, L. (2008). Enhancing Constituency Development Accountability; the Case of Bahari Constituency Development Fund. The Governance Link, issue 5, September.

Nachmias, C., \& Nachmias, D. (2000). Research Methods in Social Science (6th ed.). Newyork: Worth. 
Neely, A. (1999). The performance measurement revolution: why now and what next? International Journal of Operations \& Production Management, 19(2), 205-228. http://dx.doi.org/10.1108/01443579910247437

Neluheni, G. N. (2014, Jan.). The Role Quality Strategic Planning on Organizational Success. Mediterranean Journal of Social Sciences, (S.1) 5(1), 697.

Noble, C. H. (1999). The Eclectic Roots of Strategy Implementation Research. Journal of Business Research, 45(2), 119-134. http://dx.doi.org/10.1016/S0148-2963(97)00231-2

Nutt, P. C. (1986). Tactics of Implementation. Academy of Management Journal, 29, 230-261. http://dx.doi.org/10.2307/256187

Nyaguthii, E., \& Oyugi L. A. (2013). Influence of Community Participation on Successful Implementation of Constuency Development Fund Projects in Kenya: Case Study of Mwea Constituency. International Journal of Education and Research, 1(8), 99-123.

Obara, G. O. (2006). Challenges in Strategy Implementation at the Electoral Commission of Kenya. Unpublished $M B A$ project, University of Nairobi.

OECD. (1994). Promoting Participatory Development: From advocacy to Action. Paris OECD.

Okumu, F. (2003). A framework to implement strategies in organizations. Management Decision, 41(9).

Okungu, J. (2008). The Beauty and Shame of Kenya's Constituency Development Fund. Retrieved June 20, 2014, from http:/www.afroarticles.com/article

Parahoo, K. (1997). Nursing research: principles, process and issues. London: Macmillan.

Paul, S. (1997). Community Participation in Development Projects. The world Bank Experience, in reading in Community Participation. Washington D.C The World Bank.

Pearce, J. A., \& Robinson, Jr, R. B. (2007). Strategic Management: Formulation, Implementation and Control (10th ed.). McGraw Hill Irwin.

Rapert, M. I., Velliquette, A., \& Garretson, J. A. (2002). The Strategic Implementation Process Evoking Strategic Consensus through Communication. Journal of Business Research, 55, 301-310. http://dx.doi.org/10.1016/S0148-2963(00)00157-0

Sadiullah, K. (2006). Local Government and Participatory Rural Development. Unpublished Thesis. Gomal University.

Schaap, J. I. (2006). Toward Strategy Implementation Success: An Empirical Study of the Role of Senior Level Leaders in the Nevada Gaming Industry. UNLV Gaming Research \& Review Journal, 10, 13-37.

Schuman, H., \& Presser, S. (1981). Questions and Answers in Attitude Surveys: Experiments on Question Form, Wording, and Context. London: SAGE.

Thompson, A. A. Jr., Strickland, A. J., \& Gamble, J. E. (2007). Crafting and Executing Strategy: The Quest for Competitive Advantage, Concepts and Cases (15th ed.). Boston: Mc Graw Hill.

Viseras, E. M., Baines, T., \& Sweeney, M. (2005). Key Success Factors when Implementing Strategic Manufacturing Initiatives. International Journal of Operations \& Production Management, 25, 151-179. http://dx.doi.org/10.1108/01443570510577010

Wakaba, D. W. (2013). The Impact of CDF on Secondary Schools Curriculum Implementation in Nyahururu District, Lakipia County. Unpublished thesis. Kenyatta University.

Wernerfelt, J. P. (1984). Marketing's limited role in new product development in one computer systems firm. Journal of Marketing Research, 30, 405-21.

Yin, R. K. (2009). Case Study Research: Design and Methods (4th ed.). Sage Publication Inc. Thousand Oaks, California, USA. 